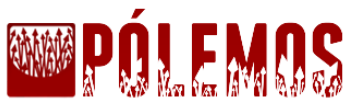

\section{O EPICURISMO E O DIREITO NATURAL CLÁSSICO SEGUNDO LEO STRAUSS. ${ }^{1}$}

\author{
Mathias Möller
}

Resumo: Busca-se, com este estudo, depreender a concepção clássica de direito natural em sua exposição epicurista segundo Leo Strauss. Para tanto, proceder-se-á com uma interpretação exegética da obra Direito Natural e História a fim de identificar a importância do epicurismo para a argumentação sustentada pelo autor na referida obra, considerando não ter recebido de Strauss abordagem especificamente a ele dirigido. Desse modo, permitir a compreensão da concepção epicurista do direito natural clássico para Strauss e como é diferenciada pelo autor das de Platão, Aristóteles e dos tomistas. Com efeito, possibilitar o esclarecimento em relação à recepção do direito natural clássico pelo moderno, o qual, a partir da confluência com o historicismo, ensejou a corrente crise de valores e a atual percepção de impossibilidade até da filosofia política conforme sustentado por Strauss.

Palavras-Chave: Filosofia Política; Leo Strauss; Direito Natural; Epicurismo; Convencionalismo; Historicismo; Positivismo.

Abstract: This study aims to deduce the classical understanding of Natural Right in the epicurist exposition according to Leo Strauss. Therefore, it will proceed with an exegetic interpretation of the work Natural Right and History in order to identify the importance of the Epicurireanism to the argumentation sustained by the author in the referred work, doing it by considering that Epicurireanism did not receive a direct approach by Strauss. In this sense, to permit the comprehension of the epicurianist conception of classic natural right according to Strauss and, in this way, on how it is differentiated by the author from those of Plato, Aristotle and the Tomist ones. With effect, to permit the elucidation of the reception of the classic natural right by modern political science. A reception which with the confluence of historicism brought about the current value crisis and the present perception of the impossibility even of the political philosophy, as sustained by Strauss.

Keywords: Political Philosophy; Leo Strauss; Natural Right; Epicureanism; Conventionalism; Historicism; Positivism;

Em 'Direito Natural e História', Leo Strauss propõe o "inquérito ao que é, por natureza, não só justo, mas também bom e belo". Propõe investigar a própria "possibilidade da filosofia" (STRAUSS, 2009, p. XIII) ${ }^{2}$, mais especificamente da filosofia política, ou seja, os "princípios imutáveis de justiça” (STRAUSS, 2009, p. 11), na medida em que discorre sobre a relação de

\footnotetext{
1 Este trabalho, em sua abordagem restrita e seu alcance circunscrito, é resultado de estudos a respeito do discurso esotérico descoberto a partir da obra de Leo Strauss ensejados pelo destacado e primoroso curso de Filosofia Política ministrado na Universidade de Brasília pelo egrégio Professor Dr. Evaldo Sampaio, a quem, em gratidão, apresento minha deferência.

${ }_{2}$ Conforme a introdução de Miguel Morgado a Direito Natural e História;
} 
convenção e natureza, sustentando a importância, para tanto, do retorno ao racionalismo político clássico. Strauss intenta a "refundação política das opiniões favoráveis ao direito natural" (STRAUSS, 2009, p. XV), de "algo bom [justo] por natureza" (STRAUSS, 2009, p. 12) enquanto ser humano, o que "decorre da investigação racional do que é intrinsecamente bom”, e não de um "conjunto subjetivo [...] ou de sistema de normas morais" (STRAUSS, 2009, p. XXXI e XXXII).

Isto posto, busca-se, com este estudo, depreender a concepção clássica de direito natural em sua exposição epicurista segundo Leo Strauss. Para tanto, proceder-se-á com uma interpretação exegética da obra Direito Natural e História, situando-se brevemente a questão em voga no contexto mais geral em que se insere, sobretudo a fim de identificar a importância do epicurismo para a argumentação sustentada pelo autor na referida obra. Assim, concentrar-se-á aqui nos capítulos 3 e 4, nos quais a filosofia epicurista é tratada com maior destaque, visto não ter recebido de Strauss abordagem especificamente a ela dirigida ${ }^{3}$. Dessa forma, pretende-se reconstituir a sequência argumentativa do autor, empregada em discurso indireto a partir de sua leitura das fontes primárias por ele abordadas, de modo a permitir a compreensão da concepção epicurista do direito natural clássico para Strauss. Para esse mister, buscar-se-á mostrar as questões atribuídas suficientemente ao epicurismo, no que tal concepção consiste, e como é diferenciada por Strauss das de Platão, Aristóteles e dos tomistas. Com efeito, possibilitar o esclarecimento em relação à recepção do direito natural clássico pelo moderno, o qual, a partir da confluência com o historicismo, ensejou a corrente crise de valores e a atual percepção de impossibilidade até da filosofia política, conforme sustentado por Strauss (STRAUSS, 1957, p. 346).

Em sua introdução a Direito Natural e História para a versão portuguesa da obra, Miguel Morgado aponta existirem para Leo Strauss três inimigos fundamentais à possibilidade do Direito

3 Na obra História da Filosofia Política, de co-edição de Strauss, Epicuro tampouco recebe um espaço específico, sendo, contudo, abordado indiretamente ao se tratar de Descartes, (STRAUSS, CROPSEY et al, 1987, p. 434); como referência para J. S. Mill na distinção qualitativa dos prazeres e para justificar sua revisão da teoria de Bentham quanto à distinção de uma vida adequada a humanos e uma adequada a animais, (STRAUSS, CROPSEY et al, 1987, p. 789); na exposição sobre Hobbes, p. (STRAUSS, CROPSEY et al, 1987, p. 433), quando tratada a ausência de ordem natural e a posição de Hobbes pela qual a razão é serva das paixões, sendo a paixão da autopreservação a maior delas e, portanto, a base para todo direito natural. Ademais, epicuristas são referidos em HFP, a saber: quando é tratada a filosofia política de Marco Túlio, (STRAUSS, CROPSEY et al, 1987, p. 159); a filosofia de Hugo Grotius, o qual defendia não haver justiça natural ao homem, afirmando ser essa uma doutrina igualmente defendida pelos epicuristas, (STRAUSS, CROPSEY et al, 1987, p. 38); quando se trata de Cícero e Marco Aurélio como contrários à posição apolítica dos epicuristas, defendendo a vida política, o que Strauss, Cropsey et al apresentam ser um denegrir da esfera política e abstrair-se de assuntos políticos, pelo que cita Epicuro em sua afirmação de necessidade de libertação pessoal da prisão dos assuntos políticos; 
Natural (STRAUSS, 2009, p. XXXVI), a saber, o historicismo, o positivismo e o convencionalismo. Neste trabalho, considerando-se o tema a ser aqui defendido, tais adversários serão abordados e suas referências em Strauss reconstituídas nesta ordem, para, então, mostrar-se com maior precisão o terceiro, no caso, os convencionalistas, cujas origens remontam aos epicuristas.

O historicismo ${ }^{4}$ aparece na obra de Strauss como deflagrador da crise da modernidade, conforme "definitivamente anunciado por Nietzsche, e depois por Heidegger" 5 , pois originou a condição do homem moderno, a qual não pode ser simplesmente esquecida. A partir do questionamento e seguida suplantação da autoridade (entendida como tradição ancestral ou verdade divina revelada) e do advir da filosofia moderna (com sua compreensão de sujeito centrada no cogito), e a reação desta quanto à primeira (STRAUSS, 2009, p. XXIV), o historicismo posicionou o humano no que Strauss considerou uma "segunda caverna, mais profunda do que a que limitava o homem grego, da qual não poderíamos sair por esforço próprio”. Essa crise de valores ocasionou também o questionamento da tradição filosófica, a saber, a filosofia grega, sobretudo em sua expressão socrática, considerada por Strauss a origem da filosofia e mais especificamente da filosofia política. $\mathrm{O}$ "caminho rumo à luz" passou a ser, então, "o retorno à ignorância natural", à primeira caverna, a socrática, e o "contato com a realidade ou com a natureza" (STRAUSS, 2009, pp. XXIV e XXV) a partir da qual se deu o início da filosofia ocidental.

4 Para Strauss, historicismo é entender que "todo pensamento humano é histórico [...] incapaz de jamais compreender algo que seja eterno [...], todo filosofar pertence essencialmente a um mundo histórico", é identificado com o convencionalismo (STRAUSS, 2009, pp. 13 e 14). O sentido histórico, criado pelo pensamento alemão, sobretudo com Hegel, que caminha para o relativismo sem reservas (STRAUSS, 2009, p. 4). Morgado limita essa conseqüência categórica do termo original inglês utilizado por Strauss, "eventually", que conforme o Oxford Dictionary significa "finalmente", tem consequência direta e final, com sua tradução em "eventualmente", que no português aventa reservas;

Conforme indica Morgado, Strauss manteve seu principal embate intelectual com Heidegger, além de Carl Schmitt e Alexandre Kojève (STRAUSS, 2009, pp. XXV e XXVII). Em História da Filosofia Política, Strauss, Cropsey et al, ao se referirem a Heidegger, apresentam o relativismo histórico como podendo ter duas distinções básicas em todos seus padrões ocorrentes, a saber: o gentil-niilismo, no qual ocorre o abandono de toda e qualquer superior aspiração humana, já que nada tem valor superior a qualquer outra coisa não há razão para buscar ou se sacrificar em prol de objetivos distantes ou árduos. O resultado, assim, é um hedonismo banal que persegue o caminho de menor resistência e, portanto, é guiado por qualquer prazer que predomine em um determinado momento. A segunda posição é o niilismo brutal, o qual, por sua vez, persegue a destruição de todos os padrões e o estabelecimento de si próprio como o ser-tudo e fim último de toda ação humana. Tal niilismo se apresenta na ciência e tecnologia na forma de conquista da natureza e na forma de política do poder com subjugação da humanidade. Com estas duas formas políticas de niilismo, as mais diversas doutrinas metafísicas terminam em reais e de certo funestas implicações morais, éticas e políticas. (STRAUSS, 1987, pp. 888 e 889); 
Tal caminho apenas seria possível ao compreender-se a "filosofia não-historicista de uma forma não-historicista", regressando "aos filósofos da antiguidade" (STRAUSS, 2009, p. 31), ou seja, às opiniões mais representativas acerca da natureza conforme o momento em que "o mundo ainda não sofrera as implicações de 2600 anos de conhecimento (STRAUSS, 2009, p. 72). Conforme argumenta Strauss, a compreensão plena da filosofia política clássica, portanto, se daria a partir do aprendizado com Platão e Aristóteles, dispensando-se "as interpretações" e "transmissões do pensamento antigo no Ocidente". Desse modo superar-se-ia as leituras enviesadas ao suprimir-se a formação ocidental que "ocultou o significado autêntico da filosofia aristotélica", como feito pela leitura cristã e tomista, por exemplo, como lembra Morgado ter reiteradamente afirmado Strauss (STRAUSS, 2009, p. XXVII).

Outro dos três grandes inimigos do direito natural, da filosofia política, segundo Strauss, então, seria o positivismo, a distinção entre fatos e valores (STRAUSS, 2009, p. XXXVI), conforme aborda no Capítulo 2 de Direito Natural e História.

Já na introdução, Strauss lança a problemática relacionada a esta questão, isto é, que a impossibilidade do direito natural equivaleria a dizer que o bom, o justo, o que é reto seria determinado exclusivamente pelos legisladores e pelos tribunais, ou seja, em acordo da e naquela polis. Situação esta que traria duas complicações, de acordo com o apontado por Strauss (STRAUSS, 2009, p. 4). Por um lado, a ignorância do fato de que todas as sociedades têm seus ideais, aquilo pelo que norteiam suas ações e crenças, e que, diante do fato de se poder vir a, com o direito positivo, determinar os próprios princípios em oposição a princípios determinados por outra sociedade, ambos poderiam ser defendidos da mesma maneira, sendo ambos igualmente válidos. De uma forma escatológica, é isso que, por outro lado, leva ao conformismo, ou, como o coloca Strauss, pela inexistência de um padrão, um ideal superior, não se seria capaz de avaliar criticamente o bom determinado pela própria sociedade, ficando-se "inteiramente escravizado pela sua sociedade" (STRAUSS, 2009, p. 5).

Importante, ainda, ressaltar que a querela de fundo nesta disputa entre fatos e valores reside na relação entre verdade da razão e verdade por revelação. É a disputa entre teologia e filosofia políticas, que, por sua vez, advém da possibilidade ou não do mundo natural ser discernível pela razão humana e universalmente reconhecido (STRAUSS, 2009, p. 11), da possibilidade de apreensão do todo (mundo, cosmo etc.) pela parte (humano, razão humana, ou mesmo indivíduo). 
Responder a essa querela em Strauss vai muito além do aqui proposto, sendo que ele próprio afirma ser isso uma questão de decidibilidade, ou seja, de opção entre "perfeição da excelência humana e das capacidades da razão humana, e a obediência à lei divina", o que é representado pelo autor na metonímia entre a sabedoria de Atenas e a de Jerusalém. Para Morgado, Strauss não pretende estabelecer pontes entre as duas cidades, pois suas rivalidades devem permanecer de pé, são “o segredo da vitalidade do Ocidente” (STRAUSS, 2009, p. XLI).

Não obstante, consoante o pensamento de Strauss, é por essa querela que a modernidade chegou à sua "compreensão científica do mundo", que "surge através de uma modificação radical da compreensão natural, por oposição ao seu aperfeiçoamento" (STRAUSS, 2009, p. 69), o que impossibilitaria a filosofia política. Para Strauss, no entanto, a ausência da comprovação empírica não é a refutação da existência, ou, como ele exemplificou quando desconstruiu a posição adotada pela sociologia quanto à impossibilidade do juízo racional a respeito de valores, “a paz não deve ser pura e simplesmente rejeitada sob o pretexto de que em parte alguma se vive em paz” (STRAUSS, 2009, p. 58), isto é, a inexistência de vida em paz não prova a sua impossibilidade em si. Para ele, ainda que vivamos em um "mundo profundamente afetado pela existência da ciência", o "mundo natural, [é o mesmo] mundo em que vivemos e agimos, [ele] não é objeto ou produto de uma atitude teorética". É nesse sentido que Strauss propõe o resgate da filosofia clássica para "reconstruir o caráter essencial do 'mundo natural' e "compreender a origem da ideia de "direito natural'” (STRAUSS, 2009, p. 70) ao que irá empenhar o $3^{\circ}$ Capítulo de seu livro.

Miguel Morgado entende que Strauss mantém sua tradicional compreensão profundamente cética e socrática quando afirma que a existência de diversas compreensões sobre a justiça entre os homens, ou seja, de como o homem deve viver, indica haver princípios de natureza que levam à percepção de injustiça no indivíduo em sociedade (STRAUSS, 2009, p. XXXI).

A partir desse ponto, Strauss passará a se empenhar em descobrir, revelar, a concepção do último da tríade de adversários ao Direito Natural, abordando o convencionalismo no Capítulo 3.

Conforme identificado por Strauss, o cerne do argumento convencionalista reside em considerar o direito como convenção por entendê-lo como resultante da cidade (STRAUSS, 2009, p. 93), que por sua vez é convencional. Assim, rejeita a justiça por estar em constante conflito com o desejo natural de cada indivíduo à medida que busca o bem próprio. Teria ele na 
justiça um bem quando lhe é benéfica enquanto integrante daquela unidade convencional. Um bem apenas para tal unidade, ou seja, podendo ser diferentemente determinado em outra unidade civil e até mesmo dentro da mesma, ao passo que pode se diferenciar na relação entre os próprios grupos, as subunidades, que a compõem. Desta feita, o bem não seria comum, mas particular, o que Platão entendeu como um bem idêntico ao prazer, o hedonismo ${ }^{6}$, em sua versão clássica, em oposição à qual Platão procura estabelecer o direito natural ${ }^{7}$.

A orientação pelo prazer, afirma Strauss, foi a primeira a substituir a orientação ancestral (a autoridade), que desvaloriza o político, e que teve, conforme sustenta Strauss, no epicurismo sua forma mais desenvolvida, exercendo maior influência ao longo dos séculos enquanto convencionalismo. Pois, de acordo com Strauss, é em sua filosofia materialista que o epicurismo se apresenta para Platão como convencionalista (STRAUSS, 2009, p. 5, apud Platão, Leis 889b890a).

Strauss resume o argumento epicurista como sustentado pelo que é "bom por natureza", garantido por ela, sentido independentemente das opiniões. Isso que é 'bom por natureza' se mostraria aos epicuristas como "aquilo percebido pelos sentidos, o que se procura desde o nascimento, antes de qualquer raciocínio, cálculo, disciplina, restrição ou compulsão". O bem é o prazer, e o prazer do corpo, primeiramente do próprio corpo (STRAUSS, 2009, p. 94).

Nesse sentido, o prazer genuíno, natural, o maior prazer, é diferente do útil, prazeroso apenas na medida em que está em função de outro bem, do bem maior. É diferente também do nobre, igualmente não prazeroso em si mesmo, pois prazeroso apenas enquanto ensejar aplauso dos outros, sendo determinado justamente a partir do que vier a ser considerado honroso (STRAUSS, 2009, p. 94). Strauss observa aqui que tal hierarquia de prazeres do epicurismo, entre os naturais necessários e os naturais não-necessários, promove "o fim ao qual tendemos por natureza", o "prazer completo" e que esse só seria acessível por meio da filosofia. Assim, Strauss destaca como que para os epicuristas o nobre é "bom por convenção", só desejável na medida em que gera prazer e evita dor, uma "justiça que só produz o prazer que se espera dela", a saber, a

6 Hedonismo ocorre utilizada por Strauss em sua obra coeditada História da Filosofia Política como referência para caracterização de posição filosófica desenvolvida em torno do prazer, como em Bacon, que, segundo Strauss, era um hedonista que rejeitou as conclusões apolíticas do hedonismo clássico, (STRAUSS, 1987, pp. 368 e 889);

7 A distinção entre natureza e convenção gira em torno do que é naturalmente bom, sendo que o hedonismo compreende que o desejo de prazer e a aversão à dor são naturais, ao que a tradição ancestral se apresentava contrária, pois desviavam o homem do caminho, sendo, portanto, proibidos pelas leis (STRAUSS, 2009, pp. 93 e 94); 
segurança. Com efeito, justiça e natureza correspondem, respectivamente, ao que se convenciona e ao que é genuíno, sendo "o direito (ou justiça) natural um symbolon, uma espécie de contrato do benefício que decorre de os homens não causarem danos uns aos outros e de não os sofrerem", conforme cita Strauss a passagem de Epicuro, constante de Rataesententiae, 31. O direito, portanto, cumpre sua função, esse é o "direito da natureza". Isto é o que Gláucon, precisamente em sua referência ao convencionalismo, em A República, de Platão, chamaria de 'a natureza do direito', “uma convenção contrária à natureza” (STRAUSS, 2009, p. 96).

Segundo Strauss, o maior documento do convencionalismo filosófico é o poema $\mathrm{Da}$ Natureza das Coisas, de Lucrécio, um epicurista que escrevera que no princípio os homens viviam "nas florestas, sem laços sociais, [...] nem restrição convencional". Fora "a sua fraqueza e o medo dos perigos dos animais selvagens que [...] levou-os a unirem-se [...] pelo prazer da segurança" (STRAUSS, 2009, p. 96). A vida genuína, natural, ou a vida original do homem, fora a vida selvagem, "a mais feliz de todas as sociedades", a qual, com a fundação das sociedades, das cidades, "deu lugar aos hábitos de bondade e fidelidade." Apenas naquela vida selvagem haveria, portanto, direito natural. Já na cidade, a vida conforme a natureza seria a do filósofo, a "única felicidade verdadeira", porém diferente da felicidade original de "um mundo finito, confiante na eternidade do universo, de seres inocentes, amistosos e dispostos a se dedicarem ao bem alheio." (STRAUSS, 2009, p. 97). O medo original, pois, dos animais selvagens e de catástrofes naturais é que levou a inocência a se tornar selvagem e o selvagem a buscar a cidade, uma 'sociedade coerciva'.

Strauss ainda acrescenta que, abalada a confiança, "os homens não tiveram outra alternativa senão procurar apoio e o consolo da crença em deuses ativos, a garantirem a segurança do mundo". Os deuses, portanto, já nascem “do receio pelo nosso mundo e da ligação que temos com ele" (STRAUSS, 2009, p. 97). O mundo "da vida por contraposição aos inanimados [...] átomos e o vazio, a partir dos quais nosso mundo se constituiu e aos quais regressará”. Para Strauss, essa crença “gerou males inomináveis”, cujo único remédio teria sido "abater as muralhas do mundo finito natural em que a religião surgiu", compreendendo que, com isso passávamos a viver "numa cidade sem muralhas, num universo [agora] infinito". Assim, "o único remédio reside em filosofar", fonte do prazer mais sólido. O povo, o homem comum, por sua vez, seria repugnado por essa vida filosófica, pois seguiria vivendo na crença do retorno à primeira sociedade, e, com isso, seguiria na anti-natural sociedade coerciva e com religião. Já "a 
filosofia requer a emancipação da ligação ao 'nosso mundo' [o mundo natural original], pois não seria possível regressar a tal simplicidade genuína nem à felicidade primeira”. Por isso, destaca Strauss, que para o filósofo epicurista a "vida dedicada à sociedade civil e ao serviço dos outros não é a vida conforme a natureza" (STRAUSS, 2009, p. 98).

Nesse ponto, Strauss passa a distinguir o convencionalismo filosófico do vulgar. Para ele, ambos concordam que "por natureza cada um procura apenas o seu próprio bem, [...], que não se dê importância ao bem dos outros". Para Strauss, o convencionalismo vulgar aparece claramente no 'discurso injusto' que Platão confiou a Trasímaco, pelo qual “o mais prazenteiro é ter mais do que os outros ou mandar nos outros" (STRAUSS, 2009, p. 98).

Como a cidade e o direito restringiram os prazeres genuínos, o maior prazer é incompatível com eles, com o que é por natureza, pois aqueles têm sua origem na convenção. Para Strauss, Hobbes diria para isso que: "a cidade e o direito têm a sua origem no desejo pela vida, e que esse desejo é pelo menos tão natural como o desejo de mandar nos outros". O convencionalismo vulgar, conforme entende Strauss, contraporia tal objeção pela compreensão de que a vida original, nua, seria como uma miséria e "uma vida miserável não é aquela que a nossa natureza procura.” (STRAUSS, 2009, p. 98). Destaca-se que Strauss apresentou ser essa a corrupção do convencionalismo filosófico, ou seja, a inibição de "um respeito sincero pela cidade e pelo direito" (STRAUSS, 2009, p. 99) e o desejo de ser superior devida ao que a posição filosófica do convencionalismo caracterizaria um "produto da vaidade e da opinião" (STRAUSS, 2009, p. 99). Strauss indica, ainda, que a cidade na percepção vulgar sacrificaria o bem maior em benefício do menor; que o desejo de superioridade cresceria nesta cidade e, por isso, a vida conforme a natureza epicurista vulgar consistiria em tirar proveito das oportunidades criadas pela convenção e pela confiança nela de modo a fazer sua ação (o seu desejo particular) se apresentar como convenção. Especificamente aí residiria a emancipação exigida pelo convencionalismo filosófico, que o vulgar passou a entender como emancipação em relação ao poder da convenção de forma a não deixá-la subtrair a oportunidade particular de prazer. Conforme apresenta Strauss, então, citando Platão em A República, a felicidade do tirano é o auge do prazer, pois ele conseguiu subordinar a própria cidade ao seu bem particular, podendo então abandonar a aparência de justiça.

O convencionalismo filosófico, em contraposição, recusa o fato de que desvalorizar o bem alheio significa poder subvertê-lo; a desejar ter mais do que os outros e ser superior a eles; o 
que poderia ser entendido como ter o bem dos outros trabalhando para o seu bem, o bem do tirano.

Para Strauss, a origem dessa corrupção do convencionalismo filosófico em vulgar se deveu aos $\operatorname{sofistas}^{8}$, pois foram eles que o publicaram, isto é, divulgaram-no e ao fazê-lo degradaram o ensinamento convencionalista pré-socrático. Em seu sentido rigoroso, são filósofos de falsa sabedoria (STRAUSS, 2009, p. 100), não de uma doutrina errônea, mas aquele que toma a verdade da parte pela do todo, a quem a "verdade deixa indiferente, ou que não ama a sabedoria”. Ainda que sabendo ser a sabedoria a excelência humana, ele mesmo por ela se interessa e dela faz uso pela honra que promove, e não pela verdade que guarda. É aquele que vive segundo o princípio que a superioridade sobre os outros é o bem maior. Em suma, um convencionalista vulgar (STRAUSS, 2009, p. 100) que aceita o convencionalismo filosófico, ou seja, que para alcançar seu bem maior, a subversão, precisa mostrar sabedoria, o que para Strauss significou ter que "ensinar que a vida conforme a natureza ou a vida do sábio consiste na combinação da injustiça efetiva com a aparência de justiça”, o que o levaria a admitir ser injusto. Isso, o faria, contudo, não conservar o bem sucedido da aparência de justiça, o que inviabilizaria a honra decorrente da sabedoria. Por fim, o sofista teria que esconder a sua sabedoria ou inclinarse a opiniões puramente convencionais. De acordo com Strauss, Platão atribuiu ao mais famoso dos sofistas, Protágoras, um mito convencionalista, o qual se baseia na diferença entre natureza, arte e convenção, sendo a justiça uma dádiva dada a todos por Zeus, efetiva apenas por meio da atividade punitiva da sociedade civil.

Ao final do Capítulo 3, Strauss anuncia que não trataria das doutrinas de direito natural pré-socráticas, mas ressalta ser importante destacar uma, ainda que rejeitada pelos clássicos, a do direito natural igualitário. Sua expressão mais simples estaria na tese de que os homens são por natureza livres e iguais, sem razão de superioridade, sendo o direito natural responsável por assegurar a restauração da liberdade natural.

Essa aparente digressão textual pode ser compreendida em função da importância que a argumentação do princípio de igualdade receberá nas doutrinas modernas. A partir dele que,

\footnotetext{
8 Strauss entende sofista como termo que pode designar um filósofo, inclusive fora esse o termo anteriormente usado em referência a filósofos, porém sofista é aqui, para ele, aquele que defende posições impopulares (que não são do povo) e que exibe seu mau gosto ao cobrar por seus ensinamentos. Para Strauss, pelo menos desde Platão, sofista passou a ser usado em oposição a filósofo e carrega sentido pejorativo (STRAUSS, 2009, p. 99);
} 
segundo Strauss, se forjou uma aliança com a doutrina da idade de ouro epicurista ${ }^{9}$ de uma natureza original em que a "liberdade e a igualdade natural eram plenamente efetivas". A modernidade, porém, guardou uma diferença significativa quanto ao fato de que a inocência originária não estaria irreparavelmente perdida e que a cidade seria indispensável, devendo-se "harmonizar [...] a sociedade civil com a liberdade e a igualdade naturais" (STRAUSS, 2009, p. 102). Para tanto, Strauss admite que a única via possível de uma sociedade civil de acordo com o direito natural seria baseada no consentimento, ou contrato, entre indivíduos livres e iguais. Ainda assim, a natureza seria vista como padrão e a sociedade civil como não-natural, e sim convencional, uma restrição da liberdade ao se dar pela corrupção da natureza. ${ }^{10}$

O Capítulo 4 de Direito Natural e História trata especificamente do direito natural clássico, desde o que Strauss considerou o início da filosofia, mais especificamente da filosofia política e a origem da tradição do direito natural. O direito natural clássico, conforme classificado por Strauss, fora desenvolvido por Platão, Aristóteles, os estóicos e os pensadores cristãos (os tomistas), e deve ser categoricamente distinguido do moderno, surgido no século XVII (STRAUSS, 2009, p. 105). Divisão esta a que remete a organização dos próprios capítulos da obra.

Desde a abertura do capítulo, Strauss adverte que a compreensão plena da doutrina clássica do direito natural, por ele sugerida para o resgate do racionalismo clássico, "exigiria a compreensão plena da mudança no pensamento operado por Sócrates”, o que afirmou não estar ao nosso alcance (STRAUSS, 2009, p. 105).

Strauss propõe uma leitura atenta dos clássicos, pela qual se perceberá que a lei deve acompanhar a ordem da natureza. Para Strauss, portanto, o "todo tem uma articulação natural". Compreender o todo não seria "compreender o todo na sua integridade [...] nem perceber a unidade que se esconde por detrás da diversidade das coisas", mas significaria "compreender a unidade que se revela na articulação manifesta do todo na sua integridade.” (STRAUSS, 2009,

\footnotetext{
9 A idade de ouro era o mundo natural ao qual o epicurista almejava retornar;

10 Para Strauss, fora a partir do exemplo malogrado de Sócrates no governo de Xantipe que o embate entre o direito natural igualitário (que concede primazia ao consentimento) e o direito natural clássico (para o qual a sabedoria goza de prioridade) levou os clássicos a recomendarem regimes mistos de governo. Uma inviabilidade fática do "regime melhor em absoluto" os levou ao melhor regime na prática, o possível, conforme Platão citado por Strauss (STRAUSS, 2009, p. 123);
} 
pp. 107 e 108). É, pois, a partir da diversidade de opiniões que se identifica justamente a possibilidade da existência do direito natural. ${ }^{11}$

Tal fundamentação é importante para entender a formação do direito natural clássico a partir das opiniões a seu respeito, sendo uma deles o epicurismo. Para Strauss, o “convencionalismo desconsidera a compreensão incorporada na opinião e apela diretamente para a natureza", o que forçara Sócrates e seus sucessores a "demonstrar a existência do direito natural nos termos escolhidos pelo convencionalismo [...], apelando aos fatos por contraposição aos discursos" (STRAUSS, 2009, p. 110). Assim, contrapunham-se à identificação do bem com o prazer, criticando, pois, o hedonismo, ou seja, o convencionalismo clássico, conforme se apresentava. ${ }^{12}$ Não se trata de um retorno ao mundo natural, ao alcance do prazer, como pensavam os epicuristas. Segundo Strauss, a liberdade clássica era percebida no fato de que "liberdade e império [o do governo do bom cidadão] são desejados enquanto elementos ou condições de felicidade", e não por "sua identificação com o bem-estar do corpo ou com a gratificação da vaidade”. A cidade, por sua vez, "não é um egoísmo coletivo”, e sim, "a atividade política [...] devidamente orientada se tiver como finalidade a perfeição humana ou a virtude". Assim, "o fim último da cidade é o mesmo que o do indivíduo", "a melhor das sociedades", a politeia "que conduz mais seguramente à excelência humana"13.

Desenvolver essa fundamentação aqui, no entanto, resultaria em se distanciar da identificação da concepção epicurista de direito natural clássico, conforme no-la apresenta Leo Strauss. Não obstante, a breve alusão acima indica o que se pode considerar o momento de inflexão do convencionalismo clássico para com as doutrinas clássicas a respeito do direito natural, conforme a abordagem dada por Strauss na obra em análise, mais especificamente no Capítulo 4.

11 Essa abordagem permite identificar o ser, "o quid", das coisas não como os "fenômenos", no que "vemos nelas, mas no que se diz sobre elas", ou seja, nas opiniões. O quid a torna identidade, a faz diferente de todas as outras (STRAUSS, 2009, p. 108);

12 De acordo com Strauss, o bem para os clássicos é essencialmente diferente do prazer, "o bem é mais fundamental do que o prazer", pois os prazeres são determinados pelas necessidades, são "elas que determinam o que pode ser prazenteiro ou não". O primordial, assim, não é o desejo de prazer, são as necessidades e o consequente desejo de satisfazê-las de acordo com a constituição natural. Assim como o homem, as necessidades também são determinadas por aquilo que as distingue enquanto ente. Um ser é bom na medida em que "em que corresponde à sua natureza e que esta requer". Para poder determinar o que é bom para o homem, então, Strauss afirma que seria preciso determinar "a ordem hierárquica da constituição natural do homem que fornece o fundamento do direito natural tal qual os clássicos o entendiam" (STRAUSS, 2009, pp. 110 e 111);

13 Conforme resgata Strauss, o termo politeia sofreu do que ele considera um erro de tradução, visto que normalmente vinha traduzido por constituição, aparecia "como fenômeno legal", sendo que "os clássicos serviam-se do termo (...) por contraposição ao termo leis” (STRAUSS, 2009, pp. 117 e 118); 
Deve-se destacar que Strauss irá classificar o direito natural clássico em três tipos de ensinamentos diferentes: o socrático-platônico, que inclui o ensinamento estóico, e por ele o cínico; o aristotélico; e o tomista (STRAUSS, 2009, p. 127). Com efeito, a limitação empenhada exime o convencionalismo dos ensinamentos do direito natural clássico, ainda que tenha servido de base para a crítica e, com ela, para a construção do ensinamento clássico ${ }^{14}$.

Diante do exposto, pode-se depreender, a partir da reconstrução da argumentação de Leo Strauss em Direito Natural e História a compreensão de direito natural segundo o ensinamento epicurista. Pode-se identificar que, para Strauss, a exposição do ensinamento epicurista denota maior importância para a formação do ensinamento clássico e a posterior abordagem de direito natural nos modernos do que propriamente de seu ensinamento em si. Isso leva Strauss a distribuir ao longo da obra as referências a ele dirigidas, apresentando uma exposição velada e de certa forma diluída desse ensinamento.

A partir de uma análise geral da obra, pode-se mesmo elucidar que o epicurismo aparece com maior frequência referido direta ou indiretamente por Strauss nas argumentações quanto às compreensões modernas de direito natural ${ }^{15}$, sobretudo no sentido de permitir entender o resgate feito por estas da compreensão epicurista, indicando inclusive a desvirtuação da doutrina clássica, conforme por ele sustentado.

Destarte apresentado, pode-se compreender a importância da participação do pensamento inaugurado por Epicuro no resgate que Strauss busca estabelecer para o retorno ao racionalismo antigo, a perspectiva greco-clássica de investigação do mundo natural, que inclui a natureza

14 No decorrer da argumentação a respeito do direito natural clássico, conforme entendido por Strauss, identifica-se ainda três referências indiretas a princípios também presentes no epicurismo. Primeiro em uma referência a Platão, pelo que Strauss desenvolve a questão do cidadão de um 'Estado mundial', uma sociedade civil fechada na qual não haveria possibilidade de guerra e não seria preciso "cultivar hábitos belicosos" em seus cidadãos. Tais cidadãos seriam livres para Platão na medida em que fossem sábios, estivessem em conformidade com a ordem da cidade natural, o que Strauss sustenta ser uma referência à condição de justiça no "princípio dos tempos, [...] um estado de ausência de escassez" (a escassez conduziria à guerra), no qual ocorreria "uma profunda afinidade entre a ideia de lei natural e a ideia de um estado original perfeito: a era de ouro ou o Jardim do Éden." Justa era de ouro à qual deseja retornar o epicurista. A segunda referência, por sua vez, ocorre quando Cícero empenha o personagem de Ático, um epicurista, para dirigir sua própria crítica à Academia de Platão de forma a reprovar a compreensão teológica-teleológica de providência em relação à doutrina estóica de lei natural, que para Cícero iria além da a doutrina de Platão do direito natural. Quanto à terceira, presente na argumentação sobre o direito natural em Aristóteles, Strauss se refere a um princípio convencionalista para explicar a desvirtuação dos ensinamentos de Aristóteles ocorrida no pensamento medieval, o qual atribuía ao clássico a deferência ao direito natural como direito positivo, "um produto da instituição humana ou da convenção" e "admitidas universalmente", o que poderia ser evitado, apregoa Strauss, com o resgate das leituras mais fiéis feitas pelos intérpretes árabes do mesmo clássico (STRAUSS, 2009, pp. 127-129, 134 e 137);

15 Identificam-se ao menos 25 referências a exposições epicuristas (STRAUSS, 2009, pp. 145, 146, 147, 148, $149,163,186,225$ e 226$)$; 
humana e, assim, a natureza das coisas políticas. Ao investigá-la desde as opiniões que originaram a filosofia política e o pensamento acerca do direito natural, Strauss busca revelar, desconstruir, a argumentação do historicismo, o qual teria instaurado a crise de valores em vigor em seu tempo, já que "não há direito natural se não houver princípios imutáveis de justiça" (STRAUSS, 2009, p. 11).

Pode-se compreender, ainda, no que tange ao epicurismo, como "a validade do historicismo depende em absoluto da negação da possibilidade de uma metafísica teorética e de uma ética filosófica ou do direito natural; depende da negação da possibilidade de se resolverem os enigmas fundamentais." (STRAUSS, 2009, p. 28).

Contribui-se, portanto, para elucidar, a partir da análise do epicurismo, como Strauss entende a clássica origem das doutrinas acerca do que é bom por natureza para o humano. Elucidar a própria importância da origem do convencionalismo moderno a partir do clássico para possibilitar a compreensão do que tratará de desenvolver sobre a percepção moderna de direito natural e sob que base ela colocou em questão a filosofia política. "Foram os apuros próprios da filosofia política do séc. XVIII que conduziram ao surgimento da escola histórica. A filosofia política do séc. XVIII era uma doutrina do direito natural.” (STRAUSS, 2009, p. 32). De forma que "uma solução adequada para o problema do direito natural não será encontrada antes desse problema básico [quanto aos princípios imutáveis de justiça na perspectiva não-historicista] ter sido resolvido" (STRAUSS, 2009, p. 8).

\section{Referências Bibliográficas}

EPICURO, LUCRÉCIO, CÍCERO, SÊNECA, MARCO AURÉLIO. Antologia de textos. 3. ed. São Paulo: Nova Cultural, col. Os Pensadores, 1985.

STRAUSS, L (ed.), CROPSEY, J. (ed.) et al. History of Political Philosophy. Chicago e Londres: The University of Chicago Press, 1987.

STRAUSS, L. Direito Natural e História. Lisboa: Edições 70, 2009.

What is political philosophy. In: The Journal of Politics. Cambridge. Vol. 19, No. 3, 1957. pp. 343-368. 